\title{
Cambios en los rituales funerarios durante la Pandemia del Covid 19 en Ecuador
}

\author{
Diego Herrera[1] \\ 1. Saludesa Ecuador, Santo Domingo de los Tsáchilas - Ecuador
}

Doi: https://doi.org/10.23936/pfr.v6i3.213

PRÁCTICA FAMILIAR RURAL | Vol.6 | No.3 | Noviembre 2021 | Recibido: 12/10/2021 | Aprobado: $20 / 11 / 2021$

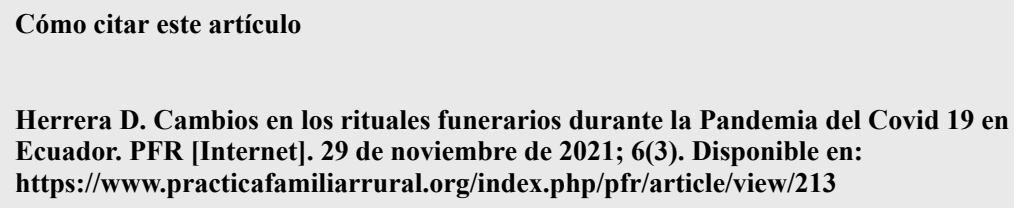

Compartir en:

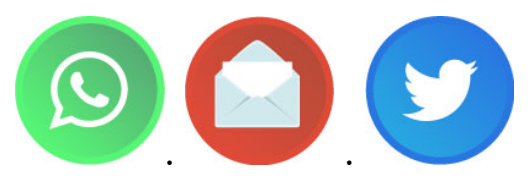

\section{Resumen}

Nancy Scheper Hughes sostiene que al morir un ser humano, muere con él su espacio, su lugar, y a la inversa, el espacio y el lugar que el individuo habitaba, pierde a quien en ellos moraba. Para estudiar la muerte se debe considerar la historia y las condiciones sociales y económicas de la persona que fallece, el poder que alcanzo cuando estaba vivo, su sistema simbólico, sus creencias, en suma, su cosmovisión (1). En el caso de los médicos su poder, curiosamente, se basa en cómo enfrentar a la inevitable muerte.

Los ritos mortuorios que practican todas las culturas sirven para darle algún sentido a la muerte. Cuando una persona fallece queda el recuerdo que no tiene que ver con cómo fue "realmente" el difunto cuando vivía, sino con el acuerdo tácito, con el que los que "quedan vivos" desean establecer como recuerdo. Aparecen entonces el verdadero sentido del ritual funerario, el cual tiene como finalidad establecer en que categoría quedara el difunto; en la "memoria" o el "olvido".

Pero, ¿qué pasa en las sociedades cuando estos rituales son suspendidos?, ¿cómo la epidemia y la cercanía de la muerte trasformo la cultura?, durante el pico de mortalidad por la epidemia del COVID 19

En el presente trabajo se aborda, el manejo de la condición humana sobre el nacimiento y la muerte en las sociedades occidentales con énfasis en el sistema medico occidental moderno. La pregunta de investigación se centra en describir, como la alta mortalidad y la suspensión de los rituales funerarios cambiaron la cultura y las relaciones sociales en el mundo mestizo. 
Palabras clave: muerte, rituales funerarios, antropología, pandemia.

\title{
Changes in funeral rituals during the Covid 19 Pandemic in Ecuador
}

\begin{abstract}
Nancy Scheper Hughes maintains that when a human being dies, his space, his place diez with him. Conversely, the space and the place that the individual inhabited lose the being who lived in those spaces and places.

To study the death of an individual, one must consider their history and socioeconmic conditions, the power they achieved in life, their symbolic system, their beliefs, and their cosmovision. In the case of physicians, their power, curiously, is based on how they confront the inevitability of death.

Los mortuarial rituals that all cultures practice serve to provide some meaning to death. When a person dies, a memory remains. This memory has little to do with how the person "actually" lived, Rather it is a tacit agreement among the living about how they wish to establish a memory of the deceased person.

But what happens in societies when these rituals are suspended? What happens when the peak of the COVID-19 pandemic and the closeness of death transform the equatorial people?

This reflection ponders the management of the human condition with regard to birth and death in western societies with an emphasis on the modern western medical model. The question under study focuses on describing how the high mortality and the suspensión of funeral rituals changed the culture and social relations in the mestizo world.
\end{abstract}

Key words: Primary non-Hodgkin lymphoma of the lung, pathology, biopsy.

\section{Introducción}

Todo relato, sea un cuento de hadas o una tragedia griega tiene su punto final, el punto final de la vida es la muerte. Todos los filósofos han reflexionado sobre la muerte, el tema es sumamente delicado pues a pesar de que siempre hablamos de la "muerte del otro", es imposible evadir su cercanía, más aún en tiempos de pandemia.

La muerte casi siempre imprevisible, trunca con la posibilidad del ser, la de la imposible realización, que significa reconocer su propia realidad, todos los sueños, objetivos, emprendimientos se transforman en nada, en un vacío. La muerte sella un relato una historia que quizás tenía un sentido.

La literatura anglosajona, que domina el pensamiento de los países más desarrollados, interpreta a la muerte dándole un aspecto positivo, dividiéndola en una buena muerte o buena manera de morir y lo no dicho, una mala muerte. Mitch Almond, visita a su antiguo profesor de sociología Morrie Schwartz, quien imparte lecciones sobre la aceptación, la comunicación y el amor en medio de su propio proceso de muerte, durante esta visita escribe la frase famosa: "La verdad es que una vez que aprendes a morir, aprendes como vivir." Transformada en varias frases que señalan la "buena muerte", como una meta de vida.(6)

Una gran cantidad de literatura popular describe enfoques positivos sobre la muerte, todos estos relatos, ilustran la idea dominante, el "como" conseguir, una buena muerte o "morir bien", que inunda el pensamiento occidental moderno. Este concepto ingenuo sobre la muerte influye profundamente en el pensamiento medico quien tienen incorporado en su práctica hospitalaria el concepto del "buen vivir", liderado por el movimiento de cuidados paliativos, quienes describen a la muerte, como una experiencia integral e individualizada o única. (16) Según un artículo médico, publicado en "The Lancet" en 1998, una buena muerte es aquella que está "libre de angustias y sufrimientos evitables para el paciente, familiares y cuidadores, de acuerdo con los deseos del paciente y de la familia, y razonablemente coherente con los estándares clínicos, culturales y éticos ". (18) 
Heidegger, pone en duda las pretensiones de control de la cultura occidental, al escribir en su obra "Ser y Tiempo: “...existen infinitas posibilidades en la vida, pero algo seguro es que una de esas posibilidades es la Muerte. Esta posibilidad está presente en todas las otras posibilidades”. (3)

Para la cultura occidental, es muy difícil aceptar que la muerte forma parte de la vida, peor aún que la muerte independientemente de la edad y las circunstancias siempre será una tragedia, a pesar de los intentos de "medicalizar", anticipar y transformar la muerte en un protocolo de actuación, ésta, siempre nos tomará por sorpresa. (14)

Esta utopía del buen morir se vio confrontada con la muerte de más de cinco millones de personas en la epidemia más grave de este siglo, tiempos de incertidumbre y de mortandad especialmente en las zonas de carencia.

El duelo, como la muerte es universal y está íntimamente ligado al sufrimiento psíquico. Concierne a todos los seres humanos. Atañe a niños y adultos que pasan por los mismos rituales. No obstante, su universalidad, los sentimientos del duelo a veces no son expresados ni reconocidos como tales; sin embargo, el duelo es necesario para poder continuar viviendo, para lograr separarse del ser perdido o amado y recobrar la libertad de funcionamiento psíquico. La perdida, produce una falta o agujero, que obliga a movilizar todo un orden simbólico que da lugar a una recomposición de significantes, en la medida en que el sujeto afronta la pérdida. (8), (9).

El trabajo de duelo, como lo llamó S. Freud, supone una elaboración intrapsíquica y a pesar de ser doloroso, es indispensable y casi obligatorio para el posterior bienestar del psiquismo humano.

Al revisar la etimología del término "duelo", vemos que se origina en dos raíces latinas, "dolus" y "duellum"; la primera hace referencia al dolor, a la vertiente más psicológica, mientras que la segunda remite a la idea de desafío que entraña el hecho de "retar a duelo"1, "al combate entre dos"(10).

Jean Paul Sartre mira la muerte como una posibilidad del ser-para-sí, pues no forma parte de su constitución ontológica, sino de su pura factcidad. (posible) Por ello mismo es impredecible y, en consecuencia, no puede ser anticipada ni menos aún esperada. La muerte, como el límite temporal absoluto, marca al ser humano de una forma única y definitiva, la muerte persigue a la imaginación y delimita el horizonte de lo pensable.

Para Lacan el duelo constituye una operación lógica subjetivante articulada necesariamente a la relación con el objeto. El duelo no consiste en sustituir el objeto perdido, sino en cambiar su relación con él. Ese cambio implica la constitución del objeto como objeto de deseo (11).

Los ritos mortuorios que practican todas las culturas, sirven para darle algún sentido a la muerte, cuando una persona fallece queda el recuerdo que no tiene que ver con cómo fue "realmente" el difunto cuando vivía, sino con el acuerdo tácito que los que "quedan vivos" desean establecer como recuerdo. Aparecen entonces el verdadero sentido del ritual funerario que tiene como finalidad, establecer en que categoría quedara el difunto: en la "memoria" o el "olvido".

\section{Metodología}

Se trata de un estudio observacional de corte cualitativo realizado de junio de 2020 a junio de 2021. Se utilizó un muestreo de conveniencia, junto con observación participativa en cuatro provincias del Ecuador, Pichincha, Santo Domingo de los Tsachilas, Manabí y Cotopaxi. Se realizo una observación participativa de los ritos funerarios de cuatro casos, y entrevistas a profundidad a doce informantes claves.

Con los datos se realizó una triangulación de la información para respaldar los argumentos claves descritos en el ensayo, es decir, los conocimientos principales de los autores se confirmaron. Al inicio del estudio no se desarrolló una metodología explícitamente antropológica debido a que la información cultural más destacada surgió de los encuentros con familiares de pacientes fallecidos por COVID 19

Las entrevistas de los estudios de caso se centraron en una comprensión más profunda de la experiencia de cercanía con la muerte y las limitaciones para la realización de los rituales funerarios, y como se vio afectada la visión del mundo y de su rol dentro de las sociedades estudiadas. 
Para entender la visión comunitaria se entrevistó a 14 personas de diferentes comunidades y diferentes posiciones sociales y económicas, 6 mujeres y 6 hombres, por localización geográfica: 3 en la provincia de Cotopaxi, 3 de la provincia de Manabí, 3 de Santo Domingo de los Tsáchilas y 3 de la Provincia de Pichincha.

2 empresarios, 2 profesores jubilados, 2 desempleados, 4 profesionales, 2 trabajadoras domésticas, 2 agricultores; a quienes se les preguntó sobre la experiencia de la muerte a causa del Covid y la restricción de realizar el ritual correspondiente. Los datos cualitativos que surgieron llevaron a las reflexiones en el presente trabajo.

\section{Resultados}

La alta mortalidad por COVID 19 trastocó las normas de comunicación y contacto del paciente con sus familiares y seres queridos. Los pacientes fueron aislados en "salas Covid", o en las unidades de cuidados intensivos "estos pacientes que están muriéndose, están solos, abandonados, al cuidado de desconocidos, sus familias o sus seres queridos no pueden permanecer a su lado, tocarlos o hablar con ellos. Se restringe el contacto del paciente, el "no ser" llega a su máxima expresión. El paciente que está consciente, mira a su alrededor otros pacientes conectados a una máquina, no se atreve a preguntar sobre su muerte: ¿Cuál es mi situación real?, ¿podré recuperarme?, ¿estoy muriéndome?

“ „,.estoy ya tres días aquí, solo puedo escribirte por teléfono, esto agota a cualquier ser humano, me tienen con oxígeno, veo como les entuban a los de las camas de alado, siento que me voy a morir... sáquenme de aqui por Dios, válete de cualquier ayuda, pero sácame..."

"La enfermedad llegó a mi familia. El hermano de mi papá está en el hospital en estado grave. Lo más triste de todo es que la familia no puede estar al lado del enfermo, alentándolo, cuidándolo mínimamente. Una verdadera soledad"

“.. el paciente que más me dolió, fue don Ulpiano, me agarraba la mano y me pedía que no le deje morir, que le ayude. Yo no quería que se muera en mi turno, me pidió ayuda para ir al baño y cuando me di cuenta ya estaba muerto ahí sentadito en el baño se murió... Yo quería renunciar ese rato y salir de ese infierno"

El Hospital es el lugar donde la muerte se normaliza, se niega, pero es prevista a través de documentos de exoneración de responsabilidad, protocolos de anticipación del duelo, estadísticas de morbilidad por servicio. La muerte pasa de ser un problema humano y religioso a un problema de funcionamiento del cuerpo o peor aún, se convierte en una cifra estadística en una curva, en una semana epidemiológica.

"Nuestro servicio a marcado un récord a nivel del país, al mantener las cifras de mortalidad más bajas entre los hospitales del Estado. Esto se debe, a la calidad de los médicos y enfermeras que laboramos en esta unidad.."

"Vamos con la semana 14 desde que inicio la pandemia y las cifras de mortalidad por Covid se mantienen, la tasa de muertes fortuitas ha aumentado, pero esos no se suman a los casos pues no tenemos evidencia de que sea por Covid......"

El hospital intenta separar al paciente de su entorno social en un fenómeno denominado, "despeje o separación de lo social". Una vez que el enfermo traspasa la entrada de la terapia intensiva, "es un no ser" que está a merced de la mirada médica, "al margen de su voluntad y de su capacidad de decisión" (12); el paciente, es separado de sus familiares las visitas son restringidas y a la familia se le entrega un informe médico, que como no están en condiciones de entender se transforma en 20 minutos de monólogo lleno de palabras técnicas. En el caso de los pacientes pediátricos la angustia es aún mayor es pues "los padres realizan una especie de acto de entrega de su hijo al médico" (13).

"Desde que ingreso a la unidad de cuidados intensivos, no sabemos nada, nadie nos avisa, el guardia nos ayuda llamando por teléfono para saber cómo esta, me dicen que necesitan referirla a otro nivel, pero no tenemos dinero para pagar una clínica privada"

El hecho de que el enfermo esté dentro de la terapia no excluye que existe "un afuera", el entorno del paciente que también está habitado. A pesar del esfuerzo médico por evitar o disimular la relación 
moribundo-entorno, que tiene por efecto apartar al enfermo de los signos del desenlace, todos saben que se está muriendo, aunque todos, actúan como si se tratase de una enfermedad que puede ser superada. (14)

"Pase tres días antes de que me entreguen el cuerpo de mi padre, estaba confundido entre los muchos cadáveres de la morgue, mi madre encerrada en la casa en cuarentena, me suplicaba que encuentre a mi padre, eso fue lo más doloroso.."

“...se murió y lo envolvieron con plásticos, ni le sacaron los sueros, con todo le envolvieron, luego envolvieron la caja también con plástico y le enterraron, no pudimos vestirle, no pudimos despedirnos, hasta ahora tengo pesadillas por esto...."

"Además de tener que lidiar con la experiencia traumatizante de la pérdida, el riesgo elevado de contagio del nuevo coronavirus impide que los cuerpos sean velados. Espero que no tenga nunca que quedar en casa inerte, en cuanto el cuerpo de su familiar está siendo incinerado sin que ningún pariente pueda despedirse o homenajear (nuera). El cuerpo de él vino dentro de un saco cerrado, no fue enterrado en un ataúd (madre). Cuando se trata de la cultura brasileña, esos ritos de pasaje que componen los rituales de despedida están tan naturalizados en lo cotidiano que su suspensión, a pesar de ser justificada, está cercada de incredulidad y sufrimiento. La sensación dominante es que un ciclo se abrió y no se completó. Lo más triste es que por encontrarnos en el medio de una pandemia, no tendrá velorio de la manera que él más amaría, con una música de la orquesta de él (nieto). El proceso de llorar al muerto y de reunirse con parientes y amigos para recibir confort y solidaridad fue sumariamente interrumpido: La cosa más triste del mundo es perder un hijo, no poder ir al entierro, no poder hacer nada. Es muy dificil, dificil, difícil. Hasta que nosotros no aguantamos más.

Otra de las pretensiones de la cultura occidental y de las instituciones hospitalarias ante la muerte es el rechazo a los cambios corporales durante el proceso de morir, siendo la muerte al igual que las secreciones del cuerpo, sucia e indecente. Los hedores y repugnancias que acompañan al moribundo son ocultados a través de la asepsia, la higiene y el maquillaje, dando una categoría moral a la fealdad de la muerte.

“... tome la decisión unilateral de cremar a mi padre, no quería que lo entierren así en menos de 24 horas. Sin que nadie le acompañe, está aquí en mi casa, al cumplir el mes lo vamos a enterrar como se debe.."

El ritual funerario permite a la sociedad diseñar una "historia", un relato, un cuento, de quien ha partido, para situarlo dentro de la memoria colectiva, o por el contrario dejar que como sujeto anónimo se pierda en el "mar del olvido" (15).

“aunque no dejaban ingresar al cementerio, me sentí en la obligación de acompañarlo en su último adiós, fue duro no poder verlo, despedirme, pero me queda esa satisfacción de que hasta la puerta del cementerio le acompañe..."

Las habitantes de Latinoamérica son en su mayoría mestizos, comparten costumbres de la cultura occidental y las culturas originarias como si los dos fuesen complementarios, a este hecho cultural, los antropólogos denominan la modernidad o también el debatido concepto de "culturas hibridas" (16).

Para la mayoría de la población mestiza cuando una persona muere el destino de su alma depende del comportamiento que haya tenido en el paso por este mundo. Si su conducta fue adecuada, su ánima se encaminará hacia el cielo, lugar donde se encontrará con Dios, con los santos católicos y con los ángeles; todos ellos lo acompañarán en la eternidad y le permitirán su descanso sin pena. Pero si la persona se condujo de forma incorrecta durante su vida su destino será el infierno, ubicado en la parte más profunda de la tierra.

Para Miguel de Unamuno (14), el éxito del cristianismo es que dio respuesta a lo que nadie pudo dar respuesta, no solo responde a una de las dos preguntas claves de la filosofía, ¿por qué morimos?, sino que además ofrece una esperanza de una nueva vida, vamos a resucitar no solo superando a la vida sino superando las enfermedades y limitaciones biológicas que hemos adquirido.

"A mi amigo le han enterrado en la tierra, recién ahora le pude visitar, le han hecho una bonita lapida, al final ya las cosas están hechas, si fuiste bueno o malo solo Dios sabrá, si los vivos te visitan bien y si ya no te visitan también..." 
El ritual funerario del mundo mestizo haciendo honor a su estética barroca, toma diferentes matices dependiendo de las zonas geográficas, regiones culturales, tradiciones, niveles socioeconómicos y creencias religiosas. Podemos encontrar una amplia gama de rituales y costumbres que describen el proceso de transición social que viven nuestras sociedades. Los rituales van desde funerales al estilo anglosajón en las grandes ciudades con flores y misas de réquiem. Otros mezclan las tradiciones de la Iglesia Católica con las del mundo andino, o montuvio, o culturas marginales, con velaciones en las casas o cementerios, novenarios, juegos de azar, consumos de café, licor y tabaco, serenatas con música que le gustaba al fallecido, hasta rituales mortuorios con el "cuerpo fuera del ataúd" mediante los cuales los individuos buscan escapar de la exclusión social. Todos estos rituales fueron proscritos en la época del Covid.

\section{"Lo peor del covid, fue ver a tanta gente conocida y querida que murió y no se les pudo dar un sepelio digno, algunos fueron enterrados como si fuesen perros, en ataúdes de cartón sin nadie que los acompañe" \\ “...en los 76 años que tengo, nunca falte, al entierro de un pariente o de un amigo, ni siquiera de un conocido, tenía mi ropa para los velorios y siempre acompañe a los dolientes y me despedi de mis amigos, son ya dos años que no voy al cementerio y me siento mal, mis hijos me envian fotos de las lapidas de mis amigos que murieron, pero no es lo mismo.."}

Todos los rituales en el mundo mestizo tienen en común el espíritu comunitario, para todos, los funerales son un acto social de reciprocidad, el romper con esta obligación significa disminuir los lazos comunitarios, promoviendo el individualismo y las relaciones dentro de la familia nuclear, la que comparte el mismo techo.

En la época prepandemia al morir un familiar los trámites administrativos relativos al fallecimiento los realizaban aquellas personas que tienen la fuerza de enfocarse en ellos, alguno de los hijos o hermanos del fallecido. Antes de la pandemia el cuerpo era recibido y arreglado en una funeraria, donde se adorna el féretro con flores e imágenes religiosas, se puede decidir tener a la vista al muerto o mantener cerrado el ataúd. La velación duraba una noche, máximo dos si se esperaba algún familiar del extranjero, los dolientes vestían de negro y recibían las condolencias de familiares y amigos quienes expresan con palabras y un abrazo su dolor ante la muerte, recordando las cualidades personales o laborales del finado. Al otro día el cuerpo era llevado a su último recinto ya sea para enterrarlo o incinerarlo, si es cremado las cenizas quedan en un nicho en el cementerio, este proceso es apoyado por un sacerdote. Una vez terminado este evento la familia y cercanos se retiran y pueden organizar o no, nueve días de oración en casa del finado.

\footnotetext{
"Los velorios fueron suspendidos, ya no es como antes si existen acompañantes y música, pero ya no es los ríos de gente que acompañaban a los velorios, la gente tiene miedo...las velaciones se realizan en la casa con una foto, solo asisten los más intimos"

"La costumbre ahora son las misas virtuales, en la que tienes que colocar un mensaje en las redes sociales, para que los dolientes sepan que estas "pendiente" de ellos, y que tenías la intención de acompañarles"
}

En áreas económicamente deprimidas, donde la posibilidad de alcanzar el éxito prometido por la modernidad y el proyecto de industrialización es casi imposible, proliferaban nuevos rituales que incluían juegos de azar, licor, música, hasta llegar a los nuevos rituales emergentes que se observan en películas y redes sociales los llamados, "velatorios fuera del ataúd" que suponen una nueva estrategia simbólica de perpetuar la vida, nuevamente la lucha entre la memoria y el olvido.

Es una manera de (per)formalidad donde con el mismo cadáver asume vida para hacer historia. La muerte social se da cuando la persona no deja huella, no trasciende y cae en el olvido (17). El mecanismo para enfrentar la muerte social de estas personas fue usando el cuerpo para asumir un último acto que se perpetúa gracias a la existencia de las redes sociales y los medios de comunicación tradicional. La muerte y el cuerpo se transforman en algo importante para la comunidad y la misma persona, lo que Achille Mbember, denomina como un "homos trascendental" que escapa al estado de sitio, en este caso a la marginación económica y la exclusión social. (18)(19)

\footnotetext{
"En Guayaquil existe hasta ahora gente que busca el cadáver de un familiar que nuca le entregaron..."

"Mi tío fue enterrado a escondidas en la comunidad, no está registrado que este muerto, pero
} 
sino hacíamos así, no nos dejaban ni salir de la casa, no hubiéramos podido despedirnos, todos teníamos Covid por esa época"

"Todas esas costumbres se han perdido, ya sea por miedo o por las restricciones, ahora existen turnos para entrar al cementerio, a nosotros nos dieron turno recién a las 5 de la tarde y delante de nosotros estaban como cinco muertos en fila, mi hermano quería que lo entierren con música y con sus amigos, nada de eso se pudo realizar..."

"La música en el cementerio, se logra mantener con una caja que suena en el carro, pero el resto es muy dificil que regrese"

“....antes del Covid murio la suegra de mi hija, le velamos en su casa, por el mall del sur en Guayaquil, en una casa grande y colocamos una carpa más grande en la calle; llegaron unas 400 personas que debíamos dar de comer, cantábamos arrullos y rezos toda la noches, pero ya no se puede, la Ley no permite, ahora vienen en pequeños grupos y se van enseguida, hasta la gente que cantaba los arullos ya está muerta..."

\section{Conclusiones}

Para la sociedad occidental el valor más importante de todos los rituales es mantener la memoria del fallecido y la interdependencia con la comunidad. El ritual funerario sea este cual fuere, no beneficia al muerto sino a los vivos. En realidad el ritual se lleva a cabo en beneficio de quienes sobreviven, conservando un rasgo identitario con la comunidad a la que pertenece, independientemente de la condición geográfica, social o económica.

El acompañamiento, en las últimas horas de vida, de parte de familiares, amigos y vecinos, supone un acto de reciprocidad que ratifica el sentido de pertenencia y asegura que cuando llegue su momento, su familia ampliada y la comunidad, le acompañaran como un acto de reciprocidad.

La muerte en el hospital alejado de familiares y amigos, supone un incremento del sufrimiento tanto para el paciente, como para su familia.

Los rituales fúnebres han mostrado a lo largo de la historia de la humanidad, marcos existenciales en el proceso de elaboración y significación de la muerte de un ser querido por parte de los que permanecen. El proceso agudo de luto desencadenado por la pérdida es importante para la salud psíquica, por ser una oportunidad para elaboración de la finitud "del otro y del sí propio". A partir del momento en que los familiares y parientes se ven impedidos de realizar los rituales de despedida debido a las restricciones impuestas, todo el proceso del luto, convierte esta etapa en un evento más doloroso e inclusive incompleto. El sufrimiento por las pérdidas de seres queridos es mayor por la dificultad del acompañamiento comunitario. Lo que se observa en gran parte de los entrevistados son duelos no resueltos o lutos complicados.

Los nuevos ritos funerarios persisten con la participación presencial de las personas más cercanas que "viven bajo el mismo techo" constituida por la familia nuclear, dejando a un lado los lazos con la familia ampliada y con la comunidad, disminuyendo, la capacidad que tenía la muerte que era convocar a la gran familia o la comunidad, que sentía que la muerte disminuía las diferencias y se convertía en la oportunidad de reforzar lazos de pertenencia.

La alta mortalidad determino la suspensión de los rituales funerarios como tradicionalmente se venían realizando en los diversos estratos sociales en el grupo estudiado, esto supuso una ruptura de los lazos comunitarios y una profundización del individualismo que la modernidad venia promoviendo.

\section{Referencias bibliográficas}

1.Scheper Hughes N. La muerte sin llanto. Violencia y vida cotidiana en Brasil Barcelona: Ariel; 1997.

2. Frankl, V. ( 1946). El hombre en busca de sentido. Barcelona, España: Herder, ISBN 978-84-254-3989-6.

3. Pausch, R. La ultima lectura Barcelona 2008

4. Meier, Ph.D., Jarred V. Gallegos, M.A., Lori P. Montross-Thomas, Ph.D., Colin A. Depp, Ph.D., Scott A. Irwin, M.D., Ph.D., Dilip V. Jeste, M.D. Defining a Good Death (Successful Dying): Literature Review and a Call for Research and Public Dialogue, 2016 American Association for Geriatric Psychiatry.

5. Hughes T, Schumacher M, Jacobs-Lawson JM, Arnold S. Confrontando la muerte: Percepciones de una 
buena muerte en adultos con cáncer de pulmón. Revista Americana de Hospicio y Medicina Paliativa ${ }^{\circledR}$. 2008;25(1):39-44. doi:10.1177/1049909107307377.

6. Ezekiel J Emanuel, Linda L Emanuel,The promise of a good death, The Lancet, Volume 351, Supplement

2, 1998,Pages SII21-SII29,ISSN 0140-6736,https://doi.org/10.1016/S0140-6736(98)90329

7. Heidegger M. Ser y Tiempo Santiago de Chile: Editorial Universitaria; 1997.

8. Lacan, J. Seminario 6. El deseo y su interpretación. Inédito.

9. Lacan, J. El Seminario. Libro 8. La transferencia. Buenos Aires: Paidós, 2003.

10. Real Academia Española, (1992). Diccionario de la lengua española. Madrid: Mateu- Cromo. Artes Gráficas

11. Lacan, J. El Seminario. Libro 10. La angustia. Buenos Aires: Paidós, 2006.

12. Comelles J. Tecnología, cultura y sociabilidad. Los límites culturales del hospital contemporáneo. In Medicina y cultura. Estudios entre la Medicina y la Antropología. Barcelona: Edicions Bellaterra; 2000.

13. Boer M. Planteos éticos de la práctica de la medicina en pacientes pediátricos con pronóstico reservado. Sus familiares y la búsqueda de alternativas terapéuticas. Rev. Hosp. Italiano. 2008; 28(2).

14. Avalos M. la Salud-Enfermedad y Muerte desde un abordaje Etnográfico. Misiones-Argentina. Revista Urguaya Antropológia. 2018; 3(1).

15. Augé M. Las formas del olvido Barcelona: Gedisa; 1998.

16. García Canclini N. Culturas Hibridas, estrategias para entrar y salir de la Modernidad: Editorial Grijalbo; 1990.

17. Thomas L. Antropología de la Muerte México: Fondo Cultural México; 1983.

18. Mbember A. Necropolitica España: ediciónes Melusina; 2011.

19. Herrera Diego, Hutchins F., Gaus D \& Troya C.(2018): Intercultural health in Ecuador: an asymmetrical and incomplete project, Anthropology \& Medicine 